\title{
The impact of the COVID-19 pandemic on resident physicians: A cross-sectional study
}

\author{
Anja Barac ${ }^{\mathrm{a}, 1}$, Paola Krnjaic ${ }^{\mathrm{b}, 1}$, Nikola Vujnovic ${ }^{\mathrm{c}}$, Nino Matas ${ }^{\mathrm{a}}$, Edita Runjic ${ }^{\mathrm{b}, *}$, Marija Rogoznica $^{\mathrm{d}}$, \\ Josko Markic ${ }^{\mathrm{e}, \mathrm{f}}$ and Antonia Jelicic Kadic ${ }^{\mathrm{e}}$ \\ ${ }^{a}$ Department of Internal Medicine, General Hospital Dubrovnik, Roka Misetica, Dubrovnik, Croatia \\ ${ }^{\mathrm{b}}$ Department of Pediatrics, General Hospital Dubrovnik, Roka Misetica, Dubrovnik, Croatia \\ ${ }^{\mathrm{c}}$ Trauma and Orthopaedic Department, General Hospital Dubrovnik, Roka Misetica, Dubrovnik, Croatia \\ ${ }^{\mathrm{d}}$ Department of Rheumatology, Rehabilitation and Physical Medicine, Hospital for Medical Rehabilitation of \\ Hearth and Lung Diseases and Rheumatism "Thalassotherapia Opatija” Ul. Marsala Tita, Opatija, Croatia \\ ${ }^{\mathrm{e}}$ Department of Pediatrics, University Hospital of Split, Spinciceva, Split, Croatia \\ ${ }^{\mathrm{f}}$ University of Split, School of Medicine, Soltanska ul., Split, Croatia
}

Received 23 November 2020

Accepted 9 April 2021

\begin{abstract}
.
BACKGROUND: COVID-19 presents a threat to the mental health of the medical staff working with COVID-19 patients. OBJECTIVE: To investigate the impact of working during the COVID-19 pandemic on resident physicians.

METHODS: The study was conducted via anonymous online survey and included resident physicians. The survey contained questions about sociodemographic information, general job satisfaction during the COVID-19 pandemic, and the impact of the COVID-19 pandemic on their personal lives.

RESULTS: This study included a response from 728 resident physicians. The majority of residents rated that the COVID-19 pandemic had a mostly negative impact on their satisfaction with professional life (59.9\%) and quality of work (62.8\%), their personal lives $(44.7 \%)$ and quality of life $(57.1 \%)$. Half of all residents indicated that they did not have enough personal protective equipment (PPE). About one-third of residents indicated that the level of stress at work during the COVID-19 pandemic was higher.

CONCLUSIONS: Working as resident physicians during COVID-19 pandemic had a negative effect on participants' professional and personal lives. Residents did not have all the necessary PPE nor felt safe working with patients with suspected or proven COVID-19. Further action is needed to provide support for physician residents working during the COVID-19 pandemic.
\end{abstract}

Keywords: Internship, residency, surveys and questionnaires

\section{Introduction}

SARS-CoV-2, a novel coronavirus which appeared in Wuhan, People's Republic of China, in December 2019, causes COVID-19 [1]. On January 30, 2020, the World Health Organisation (WHO) declared the

\footnotetext{
${ }^{1}$ These authors contributed equally to this paper

*Address for correspondence: Edita Runjic, General Hospital Dubrovnik, Roka Misetica 2, 20000 Dubrovnik, Croatia. Tel.: +385955607767; E-mail: editarunjic@gmail.com.
}

pandemic caused by COVID-19 a Public Health Emergency of International Concern [2]. Since then, COVID-19 has been quickly spreading globally, infecting the population at a very high rate [3]. Apart from serious physical complications COVID19 causes, it also presents a threat to the mental health of the infected population. Studies show that during the last epidemic, 2002 - 2004 SARS outbreak, people had severe rates of depression, anxiety, panic attacks, multiple psychotic symptoms, delirium, and an even higher rate of suicidal thoughts [4]. Medical 
staff who worked with SARS patients also showed a more frequent tendency to depression, anxiety, fear, and feeling of disappointment [4]. Likewise, medical staff caring for COVID-19 patients can develop fear for their own lives and also fear of possibly infecting themselves and their families with COVID-19 [5]. Research by Zhang et al. showed that the COVID-19 pandemic was associated with mild stressful impact in sample of 263 residents in China [6]. Several studies have shown that COVID-19 pandemic has a significantly negative impact on education and training and that good knowledge, attitude and practice are a key factor for maintain appropriate practices and low level of stress [7-10].

In Croatia, activities during the residency and education of residents are pre-determined by programs approved by the government [11]. At the beginning of March 2020, by the decision of the Minister, all physicians in Croatia were mobilized, i.e. they were subject to a work obligation, could be reassigned to another workplace, and their regular work hours could be changed [12]. This decision enabled the redistribution of work among physicians, which often placed resident physicians on the front lines of this pandemic - healthcare facilities also called COVID-19 clinics, COVID-19 emergency ambulance, COVID respiratory centres, etc. The aim of this study was to investigate the impact of work on Croatian resident physicians during the COVID-19 pandemic.

\section{Methods}

\subsection{Study design}

This study was a cross-sectional online survey.

\subsection{Inclusion and exclusion criteria}

This study included resident physicians who worked in Croatian healthcare during the beginning of COVID-19 pandemics. Residents who were absent from work during the pandemic (due to sick leave, maternity leave or similar reasons) were not included in the research.

\subsection{Data collection}

The survey was conducted from May 24 to June 15 2020, through an anonymous survey, designed for the purpose of this study, which included 51 questions (Supplementary file 1). The survey included questions about sociodemographic, general job satisfaction during the COVID-19 pandemic, and the impact of the COVID-19 pandemic on their personal lives. The survey was compiled in the Croatian language and tested by five people, including a psychologist, methodologists, a sociologist, and resident physicians. The questionnaire was then modified according to their instructions. The survey was conducted via Google Forms, and residents were contacted using their e-mail addresses (available from Croatian medical Chamber) and social network Facebook (via Facebook groups for residents).

\subsection{Data analysis}

Data were exported, and descriptive analysis was conducted using Microsoft Excel (Microsoft Corp., WA, USA). We described the sample using absolute numbers and percentages for ordinal and interval data, and median and range for nominal data. Differences among groups were analysed using the Kruskal-Wallis H test, followed by Dunn's test for pairwise multiple comparisons with Bonferroni correction. A $p$-value of less than 0.05 was considered statistically significant. Analyses were conducted using SPSS 24 (SPSS, Inc.; Chicago, IL, USA).

\subsection{Ethics}

This study was approved by the Ethics Committee of the University of Split, School of Medicine.

\section{Results}

\subsection{Characteristics of residents}

We received a response from 728 resident physicians. The characteristics of respondents are shown in Supplementary file 2.

The majority of participants (73.6\%) were women; the median age was 30 years. About half of the residents belonged to one of the following four residencies: internal medicine (18.3\%), surgery (10.9\%), pediatrics $(10.7 \%)$, and anesthesiology $(8.5 \%)$. Around half of the residents were at the fourth $(25.5 \%)$ and third (22.8\%) year of residency and onethird of them worked in the capital city (36.3\%). They worked predominantly in a University Hospitals $(37.5 \%)$ and general hospitals (30.2\%). More than half of residents $(59.8 \%)$ were separated from their families (periodically or permanently) due to their 
work in the pandemic. Most of them lived with a partner $(34.1 \%)$ or in a household, which includes children under 18 years of age (25.5\%), and only $1.5 \%$ of them lived with people aged $>65$ years.

Nearly $75 \%$ of residents reported that they worked with patients with proven or suspected COVID-19 (every day or occasionally), and $62.4 \%$ of them believed that they were more exposed to COVID19 positive patients compared to senior physicians. Half of all residents indicated that they did not have enough personal protective equipment (PPE), and $55.5 \%$ indicated that PPE was not properly deployed. In almost all cases (93\%), residents had to adapt their pre-determined resident program and $21.7 \%$ of residents indicated that they wanted to resign. Around half of the respondents (43.7\%) understood mobilization measures as an obligation.

Most residents got information about new coronavirus from scientific publications and their colleagues. Almost $17 \%$ of residents received information from the media and only $4.9 \%$ from the Ministry of Health.

During work in the COVID-19 pandemic, only $13.9 \%$ of residents had unhindered access to a

\footnotetext{
I am satisfied with my position at work during the COVID-19 pandemic

I am satisfied with the working conditions during the COVID-19 pandemic

My workload was higher during the COVID-19 pandemic

During the COVID-19 pandemic work at my institution was well organized

A potential prolongation of specialization due to work during the COVID-19 pandemic will have a positive impact on my education

The level of stress I experience at work during the COVID-19 pandemic is not higher

I am satisfied with the level of information by the employer about COVID-19 infection
}

I felt safe working with patients with a proven or suspected COVID-19 infection. While working with patients with a proven or suspected COVID-19 infection, I had all necessary personal protective equipment.

The COVID-19 pandemic makes me feel helplessness

I'm not afraid of getting infected with SARS-CoV-2 virus

I am not afraid that I will infect my loved ones with the SARS-CoV-2 virus

During the COVID-19 pandemic I did not have symptoms of anxiety more often/more expessed than before

During the COVID-19 pandemic I did not have symptoms of depression more often/more expessed than before

The level of stress I experience in free time during the COVID-19 pandemic is not higher psychologist or psychiatrist provided by the employer. Residents reported that the most significant support during the pandemic was their family $(80.5 \%)$, followed by colleagues $(50.4 \%)$ and friends (43.3\%), but $4.5 \%$ of residents reported that they did not receive support from anybody. Most residents indicated that going to nature $(80.5 \%)$, exercising (70.9\%), and spending more time with family and partners $(64.8 \%)$ would improve their quality of life during the off-duty.

\subsection{Attitudes of residents about working during the COVID-19 pandemic}

Almost half of the residents were not satisfied with their position at work and working conditions during the COVID-19 pandemic, and almost half of them agreed that their workload was higher than usual (Fig. 1). They strongly disagreed (45.7\%) that prolongation of residency will have a positive effect on their education. Residents indicated they were not satisfied with the level of information provided by the employer and predominantly did not agree with the statement that work was well organized in their

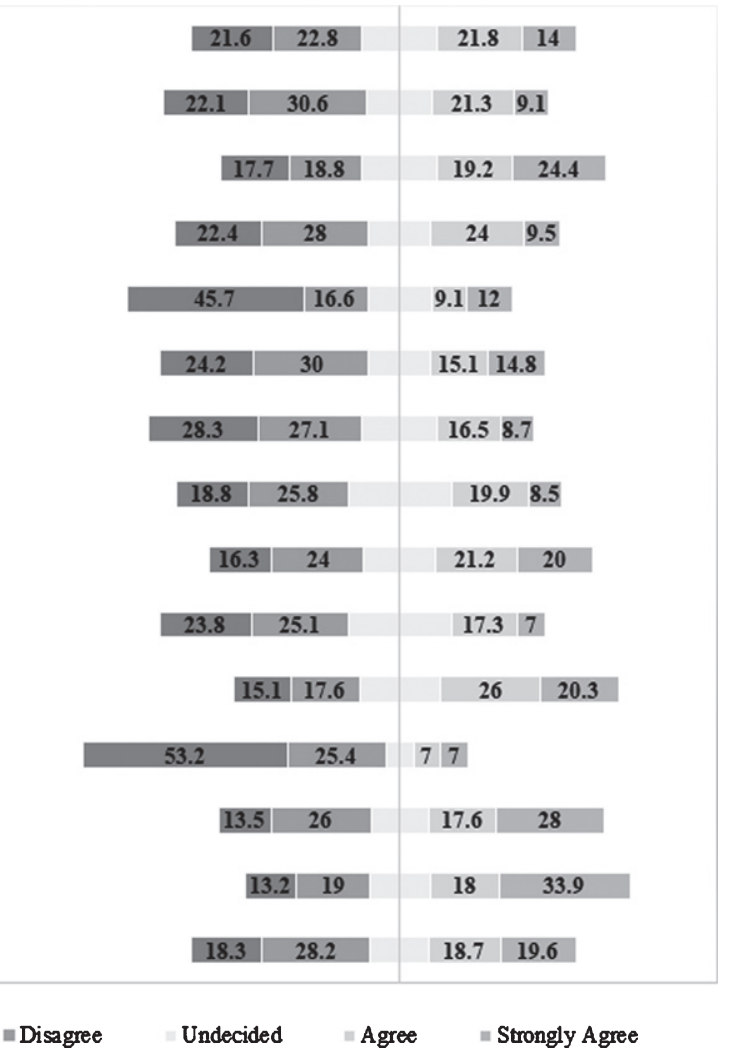

- Strongly Disagree

Fig. 1. Attitudes of residents about working during COVID-19 pandemic (reported as percentage, $\mathrm{N}=728$ ). 
institution. Almost half of them indicated that they did not have all the necessary PPE nor felt safe working with patients with suspected or proven COVID-19 (Fig. 1).

About one-third of residents indicated that the level of stress they experienced at work during the COVID19 pandemic was higher, and a quarter agreed that pandemic made them feel helpless (Fig. 1). More than half were not afraid of getting infected with SARS-CoV-2, but the vast majority indicated they were afraid that they will infect their loved ones. There were $39.5 \%$ of residents who indicated they had symptoms of anxiety or depression more often or more expressed than before; $46.5 \%$ agreed that the level of stress they experienced during their free time was higher (Fig. 1).

\subsection{Impact of the COVID-19 pandemic on the professional and personal lives of residents and their families}

The majority of residents rated that the COVID-19 pandemic had a mostly negative impact on their satisfaction with professional life (59.9\%) and quality of work (62.8\%). (Fig. 2). Most of them rated that the COVID-19 pandemic had a positive effect on collaboration with fellow residents but a negative effect on cooperation with superiors (Fig. 2).
Half of the residents indicated that satisfaction with their personal lives and quality of life was negatively affected by the COVID-19 pandemic; approximately half of them stated that the COVID-19 pandemic negatively affected their sleep quality and length of sleep (Fig. 2). However, most of the residents reported that the COVID-19 pandemic did not impact their health (53.7\%, Fig. 2).

Most residents responded that the COVID-19 pandemic did not affect their relationships or health status of the family, but it negatively affected their family quality of life (extremely negative $10.3 \%$, partly negative $36.5 \%$ ) (Fig. 2).

\subsection{Difference between groups of residents based on working with proven or suspect COVID-19 patients}

We analysed the difference in the effect of the COVID-19 pandemic on the lives of residents between a group of residents who worked all the time, periodically, or did not work with patients with proven or suspect COVID-19.

Residents that were working with COVID-19 patients had a significantly negative impact of COVID19 pandemic on their personal life $(\mathrm{H}(2)=8.25$, $P=0.016)$, quality of life $(\mathrm{H}(2)=8.04, P=0.018)$ and family's quality of life $(\mathrm{H}(2)=11.73, P=0.003)$

\section{Satisfaction with professional life Quality of work}

Collaboration with residents Collaboration with superiors

Financial income

Satisfaction with private life Quality of life Amount of free time Health condition Sleep quality Length of sleep Relationship with friends
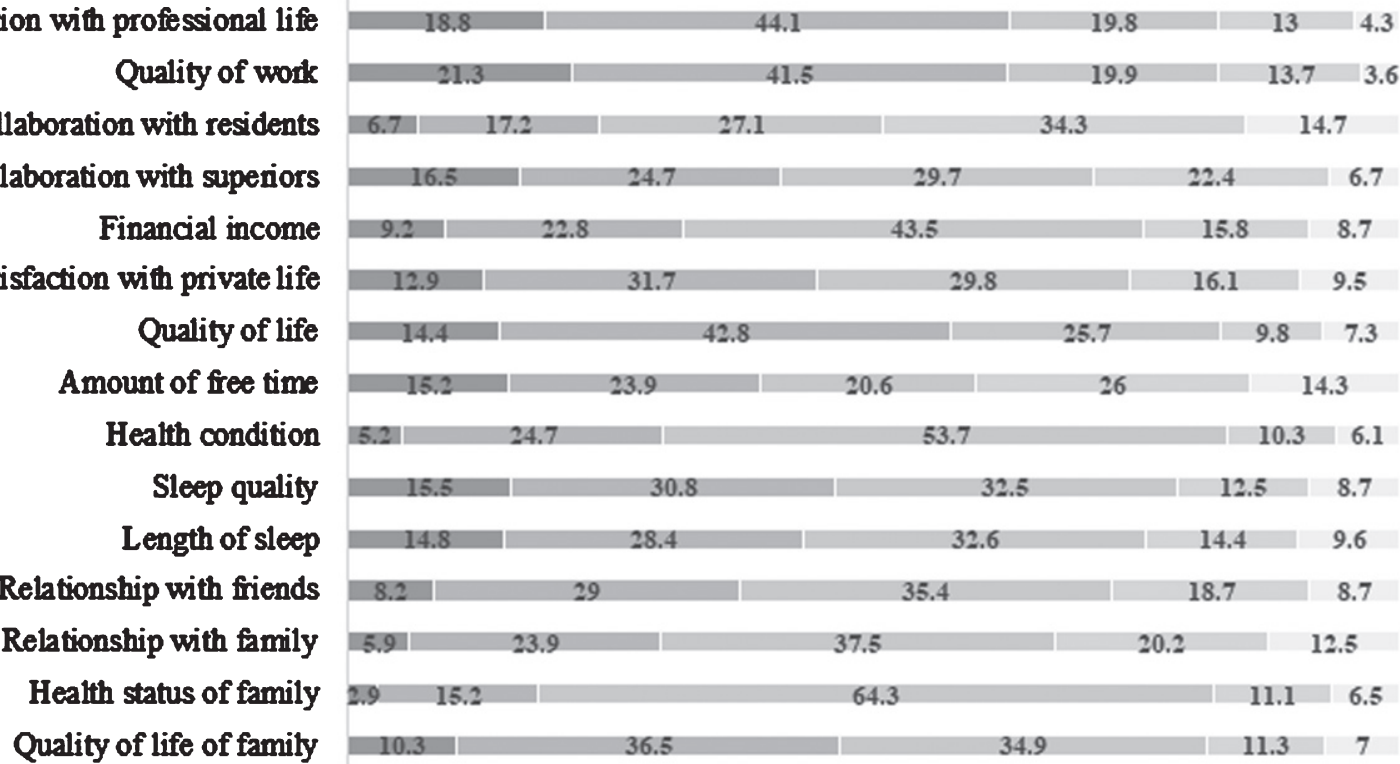

-Extremely negative $\quad$ Partly negative $\quad$ No effect $\quad$ Partly positive Extremely positive

Fig. 2. Impact of the COVID-19 pandemic on professional and personal lives of residents and their families (residents indicated in what extend work during COVID-19 pandemic affected them compared to before, reported as percentage, $\mathrm{N}=728$ ). 
Table 1

Difference in effect of COVID-19 pandemic between residents who worked all the time, periodically worked and did not work with patients with proven or suspected COVID-19

\begin{tabular}{|c|c|c|c|c|}
\hline Category & $\begin{array}{l}\text { Working with } \\
\text { patients with proven } \\
\text { or suspect COVID-19 } \\
\text { (mean rank) }\end{array}$ & p-value* & $\begin{array}{l}\text { Pairwise } \\
\text { comparison }\end{array}$ & $p$-value ${ }^{\dagger}$ \\
\hline Satisfaction with personal life & $\begin{array}{l}\text { Yes }(352.5) \\
\text { No }(401.42) \\
\text { Periodically }(350.88)\end{array}$ & 0.016 & $\begin{array}{l}\text { Yes - No } \\
\text { Periodically - No }\end{array}$ & $\begin{array}{l}0.009 \\
0.012\end{array}$ \\
\hline Financial income & $\begin{array}{l}\text { Yes }(376.88) \\
\text { No }(381.40) \\
\text { Periodically (333.09) }\end{array}$ & 0.017 & $\begin{array}{l}\text { Periodically - Yes } \\
\text { Periodically - No }\end{array}$ & $\begin{array}{l}0.035 \\
0.044\end{array}$ \\
\hline Quality of life & $\begin{array}{l}\text { Yes }(351.93) \\
\text { No }(400.30) \\
\text { Periodically }(352.61)\end{array}$ & 0.018 & $\begin{array}{l}\text { Yes - No } \\
\text { Periodically - No }\end{array}$ & $\begin{array}{l}0.026 \\
0.048\end{array}$ \\
\hline Quality of family's life & $\begin{array}{l}\text { Yes }(348.85) \\
\text { No }(407.86) \\
\text { Periodically }(350.71)\end{array}$ & 0.003 & $\begin{array}{l}\text { Yes - No } \\
\text { Periodically - No }\end{array}$ & $\begin{array}{l}0.004 \\
0.012\end{array}$ \\
\hline Amount of free time & $\begin{array}{l}\text { Yes }(337.33) \\
\text { No }(400.35) \\
\text { Periodically (373.14) }\end{array}$ & 0.003 & Yes - No & 0.003 \\
\hline Sleep quality & $\begin{array}{l}\text { Yes }(337.53) \\
\text { No }(396.43) \\
\text { Periodically (376.10) }\end{array}$ & 0.004 & Yes - No & 0.005 \\
\hline Length of sleep & $\begin{array}{l}\text { Yes }(344.32) \\
\text { No }(392.29) \\
\text { Periodically (369.96) }\end{array}$ & 0.034 & Yes - No & 0.032 \\
\hline
\end{tabular}

*Kruskal-Wallis test; †Dunn's test with the Bonferroni correction.

(Table 1). Also, residents working with COVID-19 patients all the time rated the effect of COVID-19 pandemic on their sleep quality $(\mathrm{H}(2)=10.95, P=0.004)$ and length of sleep $(\mathrm{H}(2)=6.76, P=0.034)$ significantly more negative compared to colleagues that did not work with COVID-19 patients (Table 1).

\subsection{Difference between group of residents based on separation from family during COVID-19 pandemic}

COVID-19 pandemic had significantly negative impact on personal life $(\mathrm{H}(2)=14.94, P=0.001)$, quality of life $(\mathrm{H}(2)=19.63, P=0.000)$, sleep quality $(\mathrm{H}(2)=21.62, p=0.000)$, length of sleep $(\mathrm{H}(2)=14.72, P=0.001)$ and health condition $(\mathrm{H}$ (2) $=7.68, P=0.021)$ on group of residents who were separated from family compared to those who were not separated (Table 2).

\subsection{Difference between group of residents based on sufficiency of the personal protective equipment}

Residents who indicated that they did not have enough PPE were significantly less satisfied with position at work $(P=0.000)$, working conditions
$(P=0.000)$ and organization of work in their institution $(P=0.000)$. They indicated that they felt significantly less safe $(P=0.000)$ and more afraid of getting infected $(P=0.000)$ or infecting their family with Sars-CoV-2 $(P=0.000)$. They indicated feeling more helpless $(P=0.000)$ and having more depression levels then prior to COVID-19 pandemic $(P=0.018)$. COVID-19 pandemic had significantly negative effect on their satisfaction with professional life $(P=0.000)$, quality of work $(P=0.000)$, collaboration with superiors $(P=0.000)$, health condition $(P=0.002)$, quality of life $(P=0.028)$, sleep quality $(P=0.027)$ and length of sleep $(P=0.021)$.

\section{Discussion}

Our study showed that most of the resident physicians in Croatia had to change their usual working practice due to mobilization measures adopted by the Ministry of Health and had to work with patients with proven or suspect COVID-19. Most residents were not satisfied with the organization of the work and working conditions. The majority of residents agreed that working during the COVID-19 pandemic negatively impacted their professional life, personal life, and overall quality of life. 
Table 2

Difference in effect of COVID-19 pandemic between residents based on separation from family during COVID-19 pandemic

\begin{tabular}{|c|c|c|c|c|}
\hline Category & $\begin{array}{l}\text { Separation from } \\
\text { family during the } \\
\text { COVID-19 pandemic } \\
\text { (mean rank) }\end{array}$ & $p$-value $e^{*}$ & $\begin{array}{l}\text { Pairwise } \\
\text { comparison }\end{array}$ & $p$-value ${ }^{\dagger}$ \\
\hline Satisfaction with personal life & $\begin{array}{c}\text { Yes (327.07) } \\
\text { No (393.01) } \\
\text { Periodically (372.91) }\end{array}$ & 0.001 & Yes - No & 0.000 \\
\hline Relationship with family & $\begin{array}{c}\text { Yes (338.38) } \\
\text { No }(385.76) \\
\text { Periodically (368.06) }\end{array}$ & 0.022 & Yes - No & 0.017 \\
\hline Health condition & $\begin{array}{c}\text { Yes (341.69) } \\
\text { No (386.64) } \\
\text { Periodically (361.45) }\end{array}$ & 0.021 & Yes - No & 0.017 \\
\hline Quality of life & $\begin{array}{c}\text { Yes (321.06) } \\
\text { No (392.29) } \\
\text { Periodically (383.23) }\end{array}$ & 0.000 & $\begin{array}{l}\text { Yes - No } \\
\text { Yes - Periodically }\end{array}$ & $\begin{array}{l}0.000 \\
0.004\end{array}$ \\
\hline Quality of life of family & $\begin{array}{c}\text { Yes }(320.05) \\
\text { No }(405.05) \\
\text { Periodically }(363.14)\end{array}$ & 0.000 & Yes - No & 0.000 \\
\hline Sleep quality & $\begin{array}{c}\text { Yes }(331.00) \\
\text { No }(406.68) \\
\text { Periodically }(343.79)\end{array}$ & 0.000 & $\begin{array}{l}\text { Yes - No } \\
\text { Periodically - No }\end{array}$ & $\begin{array}{l}0.000 \\
0.001\end{array}$ \\
\hline Length of sleep & $\begin{array}{c}\text { Yes }(333.33) \\
\text { No }(398.38) \\
\text { Periodically }(354.33)\end{array}$ & 0.001 & Yes - No & 0.001 \\
\hline
\end{tabular}

*Kruskal-Wallis test; †Dunn's test with the Bonferroni correction.

Around two-thirds of the residents were either every day or occasionally in contact with patients with proven or suspected COVID-19. Additionally, our analysis showed that working on the front line with COVID-19 patients had a negative effect on residents' satisfaction with personal life and overall quality of life including sleep. This is in accordance with the research of Que et al. that showed a higher prevalence of psychological problems among front-line healthcare workers during the COVID-19 pandemic [13]. Similar results were presented in studies by Civantos et al. and Khusid et al., which included urology and otorhinolaryngology residents [14-16]. These findings emphasise the need for taking action to provide support for resident physicians working with COVID-19 patients. Babamiri et al. suggested that more researches are needed to decide what type of support would be more beneficial [17].

Although it would appear beneficial for residents to take part in the pandemic, especially since pandemics are rare, most of them indicated that pandemic had a negative effect on their professional life. Also, $43.7 \%$ of residents reported higher stress on work than usual. This could be due to multiple reasons. Almost all residents $(93 \%)$ had to work in fields that are not part of their residency. Almost half of the residents $(43,7 \%)$ understood mobilization of the Ministry of Health as an obligation and $20 \%$ of them wished to quit their job. This is in accordance with earlier research on residents of urology, where a significant part of them, who were redeployed to other departments as an obligation during pandemic, stated that they would accept transfer voluntarily if they got support from their institution and had less responsibility $[14,16]$. Que et al. reported that medical workers stated they would not work on the first line if they had the choice [13]. Khusid et al. found that during the SARS outbreak residents were not satisfied with support from their institutions [16]. Almost half of the residents from our survey were not satisfied with their position at work, working conditions, and work organization in their institution during COVID-19 pandemic. Changing working conditions for medical employees is something that could create discomfort, especially among young people [13]. The fact that the virus is still new, with insufficient research about the treatment and development of the disease makes the situation even more uncertain. Everyday changes in public health recommendations from the WHO, paired with intense media reports are increasing the uncertainty about COVID-19 pandemic [18]. Thus, clear and as precise as possible information about working with COVID-19 patients or how to efficiently prevent further spread of infection are desirable. Unfortunately, only a minority of residents received the information about working with COVID-19 patients from 
employer (9.3\%) or the Ministry of Health (4.3\%). These results oblige employers and the Ministry to take action for alleviating the work and adaptation to a given situation. Better communication between the Ministry and residents could reduce problems and enhance residents' satisfaction.

Another important problem was a lack of PPE. Half of the residents reported that they did not have a sufficient amount of PPE and indicated that PPE was not equally distributed. Almost half of the residents indicated they did not feel safe enough working with patients with suspected or proven COVID-19. In research carried out among residents in New York during the COVID-19 pandemic, almost all stated that PPE was reused, and $60.4 \%$ found that PPE was suboptimal [14]. We found out that residents who did not have enough PPE were less satisfied with the quality of their work, were more afraid of infecting themselves or their family with SARS-CoV-2 and had a more negative impact on the quality of life compared to colleagues who abovementioned they had enough PPE. It is understandable that lack of PPE creates fear for one's safety, especially after first reports of physicians who were infected or deceased during the pandemic [18]. We would stress out that recommendations and rules provided by the WHO and international organizations regularly change with different situations on the field [18]. Dehghani et al. in their review, concluded that health professionals, in order to make their workplace safer, should regularly monitor changes in these recommendations [19]. We agree with Omidi et al. that regulations should be more strictly applied and the lack of PPE should be addressed by institutions to protect healthcare workers dealing with the infectious disease [20].

Finally, residents need support from their superiors, those who are responsible for their education [21]. Our survey showed that the COVID-19 pandemic harmed residents' relations with their superiors. More than half of the residents considered that they were more exposed to the disease compared to their older colleagues.

As most significant support (80\%) residents pointed out their families. Deng et al. showed that fear of family members getting infected could be one of the primary sources of stress among nurses [22]. In a study among physicians, $75 \%$ of them stated that the fact they could infect their family were highly stressful [23]. Nevertheless, we found that the COVID-19 pandemic had a more negative effect on satisfaction with personal life, quality of life including sleep and health condition in residents who were separated from family compared to those who were not separated. Organization of work in which medical workers would work in teams working for some time, then being in isolation and after having some time for spending with their families could be helpful. Around $60 \%$ of our participants stated that more time spent with their families would have a positive effect on their quality of life in general.

Many residents stated that stress levels during work and free time in the COVID-19 pandemic were higher than usual and were also paired with a decrease in quality of sleep and sleep duration, but most of them stated that levels of anxiety and depression were not higher than usual. In a previous study during the SARS outbreak, $89 \%$ of medical staff stated numerous psychological consequences of the pandemic [24]. In comparison with nonmedical staff, medical staff had more frequent cases of insomnia, depression, and anxiety [6]. We hypothesize that tracking our participants over time would indicate a higher incidence of depression and anxiety. Also, at this moment it was not possible to examine the psychological state of participants prior to the pandemic and we consider this as a limitation of our study. Another limitation of the study is its cross-sectional nature, which prevents making causal inferences.

\section{Conclusion}

The majority of surveyed residents who worked during the COVID-19 pandemic in Croatia were not satisfied with the organization of work and many indicated that the pandemic had a negative effect on their professional and personal lives. Almost half of residents did not think that they had all necessary PPE nor felt safe working with patients with suspected or proven COVID-19. Prompt action and specifically designed measures are needed to provide support for residents working during the COVID-19 pandemic.

\section{Acknowledgment}

We would like to express our very great appreciation to Livia Puljak, Mersiha Mamic Kaknjo, Svjetlana Dosenovic, Vinka Duplancic and Danijela Sunjic Egic for their valuable and constructive suggestions on the survey. We are particularly grateful to prof. Livia Puljak for reading the manuscript. Her willingness to give her time so generously has been very much appreciated. 


\section{Conflict of interest}

None declared.

\section{Data availability}

The data underlying this article will be shared on reasonable request to the corresponding author.

\section{Funding}

This research did not receive any specific grant from funding agencies in the public, commercial, or not-for-profit sectors.

\section{Supplementary data}

The supplementary files are available from https:// dx.doi.org/10.3233/WOR-205253.

\section{References}

[1] Wang D, Hu B, Hu C, Zhu F, Liu X, Zhang J, et al. Clinical Characteristics of 138 Hospitalized Patients with 2019 Novel Coronavirus-Infected Pneumonia in Wuhan, China. JAMA - J Am Med Assoc. 2020;323(11):1061-9.

[2] Huang C, Wang Y, Li X, Ren L, Zhao J, Hu Y, et al. Clinical features of patients infected with 2019 novel coronavirus in Wuhan, China. Lancet. 2020;395:497.

[3] Coronavirus disease (COVID-19) [Internet]. [cited 2020 Oct 21]. Available from: https://www.who.int/eme rgencies/diseases/novel-coronavirus-2019

[4] Maunder R, Hunter J, Vincent L, Bennett J, Peladeau N, Leszcz M, et al. The immediate psychological and occupational impact of the 2003 SARS outbreak in a teaching hospital. CMAJ. 2003;168(10):1245-51.

[5] Xiang YT, Yang Y, Li W, Zhang L, Zhang Q, Cheung T, et al. Timely mental health care for the 2019 novel coronavirus outbreak is urgently needed. Vol. 7, The Lancet Psychiatry. Elsevier Ltd; 2020. pp. 228-9.

[6] Zhang WR, Wang K, Yin L, Zhao WF, Xue Q, Peng M, et al. Mental Health and Psychosocial Problems of Medical Health Workers during the COVID-19 Epidemic in China. Psychother Psychosom. 2020;89(4):242-50.

[7] Zhong BL, Luo W, Li HM, Zhang QQ, Liu XG, Li WT, et al. Knowledge, attitudes, and practices towards COVID-19 among chinese residents during the rapid rise period of the COVID-19 outbreak: A quick online cross-sectional survey. Int J Biol Sci. 2020;16(10):1745-52.

[8] Aziz H, James T, Remulla D, Sher L, Genyk Y, Sullivan ME, et al. Effect of COVID-19 on Surgical Training Across the United States: A National Survey of General Surgery Residents. J Surg Educ. 2020;
[9] Porpiglia F, Checcucci E, Amparore D, Verri P, Campi R, Claps F, et al. Slowdown of urology residents' learning curve during the COVID-19 emergency. Vol. 125, BJU International. Blackwell Publishing Ltd; 2020. pp. E15-7.

[10] Seguí-Moya E, González-Padilla DA, Ortega-Polledo LE, Sánchez-García M, López-González JA, Antón-Juanilla M, et al. El impacto del COVID-19 en la residencia en urología en España: perspectivas y recomendaciones. Arch Esp Urol. 2020;73(5):471-8.

[11] Pederin M. European regulation of medical profession in the republic of croatia. Acta Clin Croat. 2018;57(4):736-43.

[12] Ministarstvo zdravstva Republike Hrvatske - Naslovna [Internet]. [cited 2020 Oct 21]. Available from: https://zdravlje.gov.hr/

[13] Que J, Shi L, Deng J, Liu J, Zhang L, Wu S, et al. Psychological impact of the covid-19 pandemic on healthcare workers: A cross-sectional study in China. Gen Psychiatry. 2020;33(3):100259.

[14] Breazzano MP, Shen J, Abdelhakim AH, Glass LRD, Horowitz JD, Xie SX, et al. Resident physician exposure to novel coronavirus (2019-nCoV, SARS-CoV-2) within New York City during exponential phase of COVID-19 pandemic: Report of the New York City Residency Program Directors COVID-19 Research Group. medRxiv Prepr Serv Heal Sci. 2020;2020.04.23.20074310.

[15] Civantos AM, Byrnes Y, Chang C, Prasad A, Chorath K Poonia SK, et al. Mental health among otolaryngology resident and attending physicians during the COVID19 pandemic: National study. Head Neck. 2020;42(7): 1597-609.

[16] Khusid JA, Weinstein CS, Becerra AZ, Kashani M, Robins DJ, Fink LE, et al. Well-being and education of urology residents during the COVID-19 pandemic: Results of an American National Survey. Int J Clin Pract. 2020;74(9).

[17] Babamiri M, Alipour N, Heidarimoghadam R. Research on reducing burnout in health care workers in critical situations such as the COVID-19 outbreak. Work. 2020;66:379-80.

[18] Godlee F. Protect our healthcare workers. Vol. 369, The BMJ. BMJ Publishing Group; 2020.

[19] Dehghani F, Omidi F, Yousefinejad S, Taheri E. The hierarchy of preventive measures to protect workers against the COVID-19 pandemic: A review. Work. 2020;67:771-7.

[20] Omidi L, Moradi G, Mostofi Sarkari N. Risk of COVID19 infection in workplace settings and the use of personal protective equipment. Work. 2020;66:377-8.

[21] Babacanli A, Balen I, Brechelmacher A. Satisfaction of young doctors in croatia: are we heading in the right direction? Vol. 138, Liječnički vjesnik. Hrvatski liječnički zbor; 2016 Sep.

[22] Mo Y, Deng L, Zhang L, Lang Q, Liao C, Wang N, et al. Work stress among Chinese nurses to support Wuhan in fighting against COVID-19 epidemic. J Nurs Manag. 2020;28(5):1002-9.

[23] Shechter A, Diaz F, Moise N, Anstey DE, Ye S, Agarwal S, et al. Psychological distress, coping behaviors, and preferences for support among New York healthcare workers during the COVID-19 pandemic. Gen Hosp Psychiatry. 2020;66:1-8.

[24] Lai J, Ma S, Wang Y, Cai Z, Hu J, Wei N, et al. Factors Associated With Mental Health Outcomes Among Health Care Workers Exposed to Coronavirus Disease 2019. JAMA Netw Open. 2020;3(3):e203976. 